\title{
Accounting conservatism in complex companies ${ }^{\star}$
}

\author{
Alini da Silva ${ }^{1}$ \\ (D) https://orcid.org/0000-0002-7043-5566 \\ Email: alini@furb.br
}

\author{
Alyne Serpa Ganz ${ }^{2}$ \\ (D) https://orcid.org/0000-0002-7192-6033 \\ Email: alyneserpa@hotmail.com
}

\section{Leonardo Bernardi Rohenkohl'}

(D) https://orcid.org/0000-0002-7397-9147

Email: leo_pigos@hotmail.com

\section{Roberto C. Klann ${ }^{3}$}

(D) https://orcid.org/0000-0002-3498-0938

Email: rklann@furb.br

\begin{abstract}
${ }^{1}$ Universidade Regional de Blumenau, Programa de Pós-Graduação em Ciências Contábeis, Blumenau, SC, Brazil
${ }^{2}$ Universidade Federal do Paraná, Programa de Pós-Graduação em Métodos Numéricos e Engenharia, Curitiba, PR, Brazil
\end{abstract}

${ }^{3}$ Universidade Regional de Blumenau, Departamento de Contabilidade, Blumenau, SC, Brazil

Received on 09.04.2017 - Desk acceptance on 11.08.2017 - $2^{\text {nd }}$ version approved on 05.12.2018 - Ahead of print on 10.08.2018 Associate Editor: Eliseu Martins

\begin{abstract}
This study seeks to investigate the influence of the complexity of companies on levels of accounting conservatism. The subject of analysis, accounting conservatism in complex companies, can be considered relevant because it analyzes conservative practices taking into account the organizational context of companies; something that is ignored in other studies that investigate the incentives or determinants of accounting conservatism, at least as far as firm complexity is concerned. The research presents statistical evidence that accounting conservatism varies positively with the information asymmetry caused by specific characteristics of complex environments. On the other hand, when companies present several complex characteristics together, then the trend is one of little adoption of conservatism. In addition, this research brings together evidence that aims to contribute to accounting science by analyzing complex companies and conservatism and not the opportunistic practices observed in previous studies. The sample refers to 110 publicly traded companies from 2010 to 2016 . The data collection was carried out using company reports, such as reference forms, registration data, and explanatory notes, as well as the Economatica ${ }^{\circledR}$ database. The data analysis was performed using multiple linear regression and quantile regression. The evidence obtained in the research indicates that accounting conservatism varies according to the information asymmetry caused by complex environments, in which it can present a positive relationship in companies with few characteristics of complexity, or a negative relationship if the company has complexity in several characteristics at the same time. It throws light on the different levels of conservatism observed in companies, which can often be attributed to mechanisms of governance, organizational culture, and accounting standards, among other factors, which are results that may be biased if the company complexity factor is not considered.
\end{abstract}

Keywords: accounting conservatism, firm complexity, information asymmetry, accounting information, Brazilian companies.

Correspondence address

Alini da Silva

Universidade Regional de Blumenau, Programa de Pós-Graduação em Ciências Contábeis

Rua Antonio da Veiga, 140, Sala D-202 - CEP: 89012-900

Vitor Konder - Blumenau - SC - Brazil

*Paper presented at the XVII International Conference in Accounting, São Paulo, SP, Brazil, July 2017. 


\section{INTRODUCTION}

Accounting conservatism can be observed as a mechanism of control in organizations that favor the recognition of results in the least opportunistic period, which, according to LaFond and Watts (2008) and Chi and Wang (2010), can help reduce information asymmetry. This, on the other hand, can be aggravated when companies present certain complex characteristics that, according to Liu and Lai (2012) and Jennings and Tanlu (2014), limit the transparency of information. Thus, this study intends to analyze the influence of the complexity of companies on the level of conservatism adopted in the information disclosed by firms.

Information is of the upmost importance for all and any type of organization and besides making the organization's processes slower, its disparity between users can aggravate internal and external conflicts of interest (Ndofor, Wesley \& Priem, 2015). In this aspect, costs in organizations began to be questioned by the studies from Spence and Zeckhauser (1971) and Ross (1973), seeking to align interests between agents and their superiors (Faria, Gomes, Dias \& Alburquerque, 2011), with the aim of reducing the disparity or asymmetry of information between them.

Roth and O'Donnell (1996) argue that information asymmetry can be aggravated when a company presents complex situations, with difficulties in monitoring and verifying the agent's behavior. It is thus perceived that complexity in companies can be one of the possible causes of an increase in the level of informational asymmetry.

With regard to the complexity of companies, this can be defined by organizational activities and/or phenomena that would go against the paradigm of simplicity, using a multidimensional and multidisciplinary view to observe a particular phenomenon; that is, a particular phenomenon should be analyzed in terms of different aspects (Santos \& Rodrigues, 2007).

There is not only one form of measurement for the complexity of companies. According to the literature, this can be identified in accordance with various measures, such as the number of segments that the company participates in (Barinov, Park \& Yildizhan, 2014; Baysinger \& Hoskisson, 1989; Demirkan, Radhakrishnan \& Urcan, 2012), geographical complexity (Bushman, Chen, Engel \& Smith, 2004; Cetorelli \& Goldberg, 2014; Liu \& Lai, 2012), complexity of the business (Cetorelli \& Goldberg, 2014; Jennings \& Tanlu, 2014), industrial complexity (Barinov et al., 2014; Bushman et al., 2004; Farooqi, Harris \& Ngo,
2014; Liu \& Lai, 2012), and organizational complexity (Farias, 2012; Silva, 2015).

According to Liu and Lai (2012), the complexity of companies can limit the transparency of information for users, increasing informational asymmetry. This occurs, among other things, due to a company being more concerned about the segments that generate the greatest revenue, which can result in less attention being paid to internal controls and to the generation of more concise information on the other segments or subsidiaries that are not as representative in the generation of revenue. Also, according to Jennings and Tanlu (2014), it becomes costly for agents to show information by segment of complex companies, which ultimately impairs the quality of the information for external users.

LaFond and Watts (2008) argue that one way of helping to reduce information asymmetry between investors and managers is by using a conservative form of accounting. Thus, there would be a reduction in managers' incentives to mask results, reducing asymmetric information and also organizational losses that derive from it. Another study that shows the benefits of accounting conservatism for companies with incidences of asymmetric information is the one by Chi and Wang (2010), who concluded that levels of accounting conservatism were negatively related with levels of information asymmetry. It was inferred that accounting conservatism contributes to a reduction in information asymmetry between external users, by adopting accounting practices that do not overvalue earnings.

As well as through the use of conservatism as a tool for reducing asymmetry, Silva (2015) observed that when a company reaches a high level of firm complexity, from an industrial, business, and organizational viewpoint, information asymmetry experiences a fall due to an improvement in the quality of the accounting information. In this study, the increase in the quality of the accounting information came about from a reduction in the opportunistic practices of earnings management, when the company reached high indices of complexity.

It follows that when a company presents complex activities, the managers may adopt conservatism instead of opportunistic practices, due to internal controls or external pressures to reduce information asymmetry. However, it is worth mentioning that accounting conservatism can be motivated by numerous other causes, such as taxation factors, accounting standards, culture, and manager remuneration, among others. Nonetheless, this study 
proposes to observe this practice from the perspective of the complexity of the activities of companies.

Thus, this study is guided by the following question: what is the relationship between accounting conservatism and firm complexity? The aim is to discover the influence of the complexity of companies on the levels of accounting conservatism.

This study presents evidence that aims to contribute to accounting science and to organizational studies, by analyzing the mitigation of informational asymmetry in complex companies due to the use of conservatism instead of the reduction in opportunistic practices observed by international studies, such as those by Demirkan et al. (2012), Barinov et al. (2014), Farooqi et al. (2014), and Jennings and Tanlu (2014).

In addition, besides the studies from LaFond and Watts (2008) and Chi and Wang (2010), already mentioned previously, the study from Almeida (2010) can be observed, which analyzed accounting conservatism and earnings management, among others, in competitive environments, concluding that the practice of conservatism was adopted to a greater degree in such environments to reduce asymmetries and make the company attractive to the market. However, this study differs from the one from Almeida (2010) by addressing the complexity of companies, instead of the competitiveness of the environment.

Due to the lack of research in the area on the relationship between the complexity of companies and conservatism, as well as considering the literature that affirms that companies with a higher level of complexity have greater information asymmetry, this study is warranted for its analysis of conservatism as a way of limiting informational asymmetry in complex companies. It may, therefore, shed light on the different levels of conservatism observed in companies, which can often be attributed to mechanisms of governance, organizational culture, and accounting standards, among other factors, which are results that may be biased if they do not consider the firm complexity factor, which could explain some of the empirical differences observed.

\section{ACCOUNTING CONSERVATISM}

Within the different sets of accounting practices and procedures, the analysis regarding the relationship between conservatism and accounting regulation and its causalities is still in its infancy and/or inconclusive in the Brazilian literature (Santos \& Costa, 2008). According to Scalzer, Beiruth, and Reina (2017), Brazilian studies have observed mixed results in relation to accounting conservatism and accounting standards, presenting results with positive and negative relationships and even results with no statistical significance.

A review of the literature reveals the separation of accounting conservatism into conditional and unconditional. Unconditional conservatism is less researched due to it lacking consolidated metrics. By definition, it is taken that when evaluating wealth, minimum values should be chosen for assets/revenue and maximum values should be chosen for liabilities/ expenses (Paulo, Antunes \& Formigoni, 2008).

Ball and Shivakumar (2005) describe conditional conservatism as the accounting tendency to recognize economic losses more quickly than gains. The adoption of conservative practices is stimulated by the debt market (Ball, Kothari \& Robin, 2000) and by mechanisms of corporate governance (LaFond \& Watts, 2008).
With regard to conditional conservatism, accounting traditionally expresses and knows it as the principle of not recognizing earnings in advance but doing so for losses (Bliss, 1924), and where choosing less optimistic options is considered to be positive. For Basu (1997), the interpretation of this principle is the level of verification of information by external users, in which "good news" denotes gains and "bad news" denotes losses.

Bad news is, in summary, a proxy for negative returns, timelily and more fully recognized in the results than good news, measured by positive returns (Banker, Basu, Byzalov \& Chen, 2016; Basu, 1997). However, regardless of how much the recognition of assets/revenues and liabilities/expenses is asymmetric, these aim to help in reducing informational asymmetry (LaFond \& Watts, 2008) by disclosing a conservative result instead of an opportunistic one.

For Watts (2003), the explanation for the disclosure and use of this information asymmetrically lies in the intense connection between conservatism and contractual relations, with the intention of ensuring minimum guarantees for affairs in relation to pre-established obligations. Also, for the author, in contract terms, the growth of company value is observed through the use of 
conservatism, since this restricts opportunistic behavior by managers, keeping the disclosed accounting numbers more neutral.

The relationship between conservatism and the quality of accounting information is controversial, especially after the International Accounting Standards Board (IASB) revised the framework and removed conservatism from the condition of faithful representation, since it is inconsistent with neutrality. In the end, would conservative accounting practices be beneficial to the quality of accounting information or not? Would information free from bias (neutral), as prescribed by the IASB, accept conservative accounting practices?

Despite the academia not yet offering a definitive answer to these questions, authors (LaFond \& Watts, 2008) who study conservatism reflect on its importance to companies and consider it to be a mechanism of governance in companies that contributes to reducing information asymmetry, restricting the administration's ability to manage and possibly overstate their financial performance. Therefore, conditional conservatism can be considered a limiter of the recognition of excessively optimistic earnings and a mechanism of control that has an impact on reducing asymmetry and on the quality of information.

From this perspective, despite accounting conservatism producing possibly biased (non-neutral) information, it nonetheless has the ability to improve the quality of accounting information, mitigating opportunistic practices that could lead to artificially inflated results, which might be more prejudicial to the users of the accounting information than less optimistic information.

To verify companies' adherence to accounting conservatism, different measurement models can be used, the most recognized one being that of Basu, from 1997. Recently, with the aim of enhancing the Basu model, Banker et al. (2016) proposed a modification, combining the theory of conservatism from financial accounting with cost asymmetry from cost accounting.

The authors analyzed the Basu (1997) model and showed an error of approximately $25 \%$ in the estimation of conservatism caused by not controlling for cost asymmetry. This is due to the fact that the positive variation (increase) in costs in periods of greater sales is higher than the negative variation (reduction) in periods of falls in sales. Thus, the authors proposed the inclusion of cost asymmetry variables in the original Basu (1997) model to correct this estimation error (Banker et al., 2016).
Another model used to measure conservatism is that of Khan and Watts (2009), which helps to identify this at a company level, also adapting the Basu (1997) model. The authors included variables such as the size, market-tobook, and leverage of each company in the original model to identify its level of conservatism, called the C_Score.

In light of the above, it is considered that conservative accounting practices, observed by models such as those from Basu (1997), Khan and Watts (2009), and Banker et al. (2016), can help in reducing the informational asymmetry between companies and their various stakeholders, which may be interesting especially for complex companies, which are characterized by environments with greater informational asymmetry.

\subsection{Complexity of Companies and Formulation of the Hypotheses}

Company complexity is understood as an increase in different organizational elements, which should be treated simultaneously by the organization. Company complexity can be regarded as an ambiguity in an organization and difficulty knowing and understanding the organizational operations (Jennings \& Tanlu, 2014).

It can be inferred that company complexity refers to specific characteristics that contradict the paradigm of simplicity in their business operations (Santos \& Rodrigues, 2007). These characteristics can be divided and/or measured in a number of groupings, such as industrial, business, and organizational complexity (Silva, 2015).

Complexity was primarily analyzed in accounting in the area of strategy, in the area of finance, and currently, studies in financial accounting can be observed, more specifically regarding the quality of accounting information (Barinov et al., 2014; Demirkan et al., 2012; Farooqi et al., 2014; Jennings \& Tanlu, 2014; Silva, 2015).

According to the literature (Barinov et al., 2014; Demirkan et al., 2012; Farooqi et al., 2014; Jennings \& Tanlu, 2014; Liu \& Lai, 2012; Silva, 2015), the complexity of a company can limit the transparency of operations and information for external users, which can aggravate information asymmetry.

Jennings and Tanlu (2014) argue that as a company becomes organizationally complex, it will be more costly and difficult for managers to analyze the really relevant information to be disclosed to the market. This can compromise the quality of communication between the company and external users, increasing informational asymmetry. 
To reduce this asymmetry, Watts (2003), LaFond and Watts (2008), and Chi and Wang (2010) highlight conservatism as an important attribute of the disclosure of financial information, acting as a mechanism of control that can limit agency conflicts. Thus, it is inferred that this attribute of accounting information could help in reducing information asymmetry in complex environments.

Almeida (2010) observed that in competitive environments, which present a similar measurement of complexity, the degree of accounting conservatism is increased, in order to reduce asymmetries and make the company attractive to the market in relation to the competition.

Among the measures of complexity, industrial complexity can be measured, according to Liu and Lai (2012), Barinov et al. (2014,) Farooqi et al. (2014), and Silva (2015), using the Herfindahl index and its extensions, calculated by the ratio of the sales in each segment of the industry to the company's total sales (Barinov et al., 2014; Hou \& Robinson, 2006). Industrial complexity can compromise the quality of communication between users, thus increasing information asymmetry (Barinov et al., 2014). To help reduce this asymmetry, companies can adopt differentiated levels of accounting conservatism. This leads to the first research hypothesis being outlined:

$\mathrm{H}_{1}$ : the greater the industrial complexity, the greater the degree of accounting conservatism.

The complexity of the business can be observed via the quantity of segments the company operates in (Cetorelli \& Goldberg, 2014; Demirkan et al., 2012; Doyle, Ge \& Mcvay, 2007; Jennings \& Tanlu, 2014; Silva, 2015), which represent the diversification of its operating areas. According to Liu and Lai (2012), an increase in asymmetry can be caused, among other factors, when companies disclose more detailed information solely on the main operating segment, reducing the transparency of information about the others. External users will know the aggregated cash flows of complex companies, but not the individual ones by operating segment (Liu \& Lai, 2012). Thus, the second hypothesis is presented, namely that conservatism can be used to a greater degree in this situation of business complexity, in order to help reduce asymmetry:
$\mathrm{H}_{2}$ : the greater the complexity of the business, the greater the degree of accounting conservatism.

Organizational complexity can be measured by the quantity of subsidiaries that the company has (Cetorelli \& Goldberg, 2014), which represents its fragmentation, as well as by its size, by the number of years operating in the market, by the long term debts, by the capital structure, and by the profitability that it presents (Farias, 2012; Silva, 2015).

The size of the company represents its diversification in terms of assets (rights and goods) (Silva, 2015), age is related to the organizational life cycle (Boone, Field, Karpoff \& Raheja, 2007; Farias, 2012), long term debts and capital structure show the company's financial diversity (Farias, 2012; Linck, Netter \& Yang, 2008; Silva, 2015), and finally, its profitability represents the complexity of the organization's earnings (Cardinaels, Roodhooft \& Warlop, 2004). These measures have an impact on the way the company is managed, which makes it complex and can sometimes incentivize managers to adopt conservative accounting practices to mitigate the information asymmetry resulting from this context. Thus, the third hypothesis is presented:

$\mathrm{H}_{3}$ : the greater the organizational complexity, the greater the degree of accounting conservatism.

In light of the above, it is believed that in an environment of firm complexity, whether industrial, organizational, or business-related, a company, equipped with internal controls or even due to external pressures from investors, can adopt accounting practices to reduce the informational asymmetry caused by the complexity of its organizational operations, such as accounting conservatism, for example, given that this reduces the management's ability to exaggerate or even manipulate its financial performance (LaFond \& Watts, 2008). Thus, the fourth and last research hypothesis is outlined, with the aim of jointly capturing industrial, business, and organizational complexity in a single measure. The objective is to evaluate whether, in the presence of high levels of complexity in different characteristics, companies are concerned about adopting a greater level of accounting conservatism.

$\mathrm{H}_{4}$ : the greater the total complexity of companies, the greater the degree of accounting conservatism. 


\section{METHODOLOGICAL PROCEDURES}

The population of the study comprised all the companies listed on the São Paulo Stock, Commodities, and Futures Exchange (BM\&FBOVESPA). The sample was composed of 110 companies with available information on all the variables and the period analyzed. The analysis period covered 2010 to 2016, due to the adoption, from 2010 onward, of the IASB accounting standard that foresees the attribute of neutrality in the qualitative characteristic of faithful representation (Accounting Pronouncements Committee, 2011 - CPC 00) instead of the accounting principle of prudence and/or of the convention of conservatism, present in the local accounting norms before 2010 .

In this study, the choice was made to only analyze Brazilian companies, due to this being considered an adequate and sufficient sample to test the hypotheses, as well as due to the unavailability of information on the complexity of companies from other countries.

The data concerning the accounting conservatism models and the organizational complexity variables company size (SIZE), profitability (ROE), long term debts (LTD), and capital structure (CS) were collected from the Economatica ${ }^{\circledR}$ database. The data used to calculate industrial complexity (IC) and business complexity (BC) were collected from the explanatory notes. The data on the quantity of subsidiaries (SUB) that the companies had were collected from the reference forms, while the years in operation (YO) variable for the companies was collected from the registration data available from the BM\&FBOVESPA website; both (YO, SUB) also compose the organizational complexity group. Below, the accounting conservatism models used are presented:

$$
P L S_{i t} / P_{i t-1}=\beta_{0}+\beta_{1} R_{i t}+\beta_{2} D_{i t}+\beta_{3} D_{i t} * R_{i t}+\varepsilon_{i t}
$$

in which $P L S_{i t}$ is the accounting result for the period (profit/loss) per share of company $i$ in year $t, P_{i t-1}$ is the average price of the share of company $i$ in year $t-1, R_{i t}$ is the log-transformed return on the share of company $i$ in year $t, D_{i t}$ is the dummy variable that takes the value of 1 when the return on the share of company $i$ in year $t$ is negative and 0 otherwise, and $D_{i t}{ }^{*} R_{i t}$ is the difference between the impact of the positive and negative returns. Conservatism implies that this coefficient $\left(\beta_{3}\right)$ is positive because bad news (negative returns) will be reflected to a greater extend in profit than good news (positive return).

Equation 1 represents the Basu (1997) model, which demonstrates the level of accounting conservatism via the coefficient $\beta_{3}$. According to Basu (1997), $\beta_{2}$ represents both positive and negative return, while $\beta_{3}$ only represents negative return. If $\beta_{3}$ is positive, it shows the presence of accounting conservatism via the timely recognition of negative returns. However, according to Banker et al. (2016), this model can present bias in the estimation of the coefficient caused by cost asymmetry.

In the study by Banker et al. (2016), in which one of the authors is also Sudipta Basu, the aim was to reformulate the Basu (1997) model in an attempt to neutralize cost asymmetry. Thus, in this study the Banker et al. (2016) model was also used to capture the conditional conservatism in the companies of the sample and compare with the coefficient calculated by the original Basu (1997) model. Model 2 refers to the Banker et al. (2016) accounting conservatism model.

$$
\begin{gathered}
P L S_{i t} / P_{i t-1}=\beta_{0}+\beta_{1} R_{i t}+\beta_{2} D_{i t}+\beta_{3} D_{i t} * R_{i t}+\beta_{4} D S_{i t}+\beta_{5} \Delta S_{i t} / P_{i t-1} \\
+\beta_{6} D S_{i t} * \Delta S_{i t} / P_{i t-1} v_{i t}
\end{gathered}
$$

in which $D S_{i t}$ is the dummy variable, equal to 1 if there is a fall in sales from year $t-1$ to year $t$ and 0 otherwise, $\Delta S_{t} / P_{i t-1}$ is the change in sales from year $t-1$ to year $t$ (variation in sales) dimensioned (divided) by the market value of the shares (share price) at the start of the fiscal year, and $D S_{i t}{ }^{*} \Delta S_{t} / P_{i t-1}$ is the multiplication of the variables $D S_{i t}$ and $\Delta S / P_{i t-1}$, which represents the level of cost asymmetry of the companies, if the coefficient is shown to be positive.

In addition to the models presented, this study also analyzes the Khan and Watts (2009) model, which uses the G_Score and the C_Score to determine the timely 
recognition of good and bad news, respectively. This model, unlike the Basu (1997) and Banker et al. (2016) models, enables the measurement of the individual conservatism for each company based on its general model, from which the coefficients are captured and the C_Score (proxy for conservatism) is determined based on the size, market-tobook, and leverage of each company. The Khan and Watts (2009) model is presented in equation 3.

$$
\begin{gathered}
P L S_{i t} /_{P_{i t-1}}=\beta_{0}+\beta_{1} D_{i t}+\beta_{2} R_{i t}\left(\mu_{1}+\mu_{2} \text { Size }_{i}+\mu_{3} M / B_{i}+\mu_{4} \text { Lev }_{i}\right) \\
+\beta_{3} D_{i} R_{i}\left(\lambda_{1}+\lambda_{2} \text { Size }_{i}+\lambda_{3} M / B_{i}+\lambda_{4} \text { Lev }_{i}\right) \\
+\left(\delta_{1} \text { Size }_{i}+\delta_{2} M / B_{i}+\delta_{3} \text { Lev }_{i}+\delta_{4} D_{i} \text { Size }_{i}+\delta_{5} D_{i} M / B_{i}+\delta_{6} D_{i} \text { Lev }_{i}\right)+\varepsilon_{i t}
\end{gathered}
$$

in which Size $_{i}$ is the size of the company according to the natural logarithm of the market value, $M / B_{i}$ is the market-to-book, Lev $_{i}$ is the leverage measured by the long term and short term debt deflated by the market value, and $\mu_{i}$ and $\lambda_{i}$ are constant empirical estimators for all the companies, but which vary according to time, estimated using annual cross-sectional regressions.
With the estimators generated by equation 3 , the $\mathrm{G}_{-}$ Score and the C_Score are calculated using equations 4 and 5 , stressing that these are not regression models, but rather equations for obtaining the conservatism index for each company according to the good news (G_Score) and bad news (C_Score).

$$
\begin{gathered}
G_{-} \text {Score }=\beta_{3}=\mu_{1}+\mu_{2} \text { Size }_{i}+\mu_{3} M / B_{i}+\mu_{4} \text { Lev }_{i} \\
\text { C_Score }=\beta_{4}=\lambda_{1}+\lambda_{2} \text { Size }_{i}+\lambda_{3} M / B_{i}+\lambda_{4} \text { Lev }_{i}
\end{gathered}
$$

The Khan and Watts (2009) model, expressed by equation 3, includes equations 4 and 5 in the original Basu (1997) model, expressed by equation 1 , with the addition of the terms in the final brackets, which are needed to control the characteristics of the companies separately. Thus, in the presentation and analysis of the data, the three models (Banker et al., 2016; Basu, 1997; Khan \& Watts, 2009) are used for the initial analysis in order to observe the level of measurement of conservatism based on each equation.

In addition, the Khan and Watts (2009) model was used to observe the individual conservatism of the companies based on the C_Score. The Banker et al. (2016) model, adapted based on the Khan and Watts (2009) methodology, was also measured to observe the C_score of each company, in whose model there is a cost asymmetry correction, presented by equation 6 .

$$
\begin{gathered}
P L S_{i t} / P_{i t-1}=\beta_{0}+\beta_{1} D_{i t}+R_{i t}\left(\mu_{1}+\mu_{2} \text { Size }_{i}+\mu_{3} M / B_{i}+\mu_{4} \text { Lev }_{i}\right)+D_{i} R_{i}\left(\lambda_{1}+\lambda_{2} \text { Size }_{i}+\right. \\
\left.\lambda_{3} M / B_{i}+\lambda_{4} \text { Lev }_{i}\right)+\left(\delta_{1} \text { Size }_{i}+\delta_{2} M / B_{i}+\delta_{3} \text { Lev }_{i}+\delta_{4} D_{i} \text { Size }_{i}+\delta_{5} D_{i} M / B_{i}+\delta_{6} D_{i} \text { Lev }_{i}\right) \\
+D S_{i t}\left(\rho_{1}+\rho_{2} \text { Size }_{i}+\rho_{3} M / B_{i}+\rho_{4} \text { Lev }_{i}\right)+\Delta S_{i t} / P_{i t-1}\left(\tau_{1}+\tau_{2} \text { Size }_{i}+\tau_{3} M / B_{i}+\tau_{4} \text { Lev }_{i}\right) \\
+D S_{i t} * \Delta S_{i t} / P_{i t-1} v_{i t}\left(\varphi_{1}+\varphi_{2} \text { Size }_{i}+\varphi_{3} M / B_{i}+\varphi_{4} \operatorname{Lev}_{i}\right)+\varepsilon_{i t}
\end{gathered}
$$

With the coefficients $\mu_{i}$ and $\lambda_{i}$ of the model from equation 6, the G_Score and the C_Score that there would now be with the cost asymmetry correction were calculated. With these coefficients of individual accounting conservatism originating from the Khan and Watts (2009) and Banker et al. (2016) models adapted from Khan and Watts (2009), new models with annual company complexity data were run, in order to observe the main relationship of the study between the complexity of companies and accounting conservatism. Table 1 presents the complexity variables. 
Table 1

Research construct

\begin{tabular}{|c|c|c|}
\hline Variable & Description & Authors \\
\hline $\begin{array}{l}\text { Accounting conservatism } \\
\text { coefficient }(\mathrm{ACkw})\end{array}$ & C_Score of the equation from Khan and Watts (2009). & Khan and Watts (2009) \\
\hline $\begin{array}{l}\text { Accounting conservatism } \\
\text { coefficient (ACkwb) }\end{array}$ & $\begin{array}{c}\text { C_Score of the equation from Banker et al. (2016) adapted to the } \\
\text { methodology of Khan and Watts (2009). }\end{array}$ & $\begin{array}{l}\text { Banker et al. (2016) adapted } \\
\text { to the methodology from Khan } \\
\text { and Watts (2009) }\end{array}$ \\
\hline Industrial complexity (IC) & $\begin{array}{l}1-\left(\mathrm{HHI}=\sum^{\mathrm{N}}{ }_{\mathrm{i}=1} \mathrm{~s}_{\mathrm{i}}{ }^{2}\right) \\
\text { Herfindahl index, which measures the share of sales of each segment of the } \\
\text { company in relation to the company's total sales, which varies from } 0 \text { to } 1 . \\
\text { Coefficient close to } 1 \text { represents high complexity. }\end{array}$ & Barinov et al. (2014) \\
\hline Business complexity (BC) & Measured by the quantity of segments in which the company participates. & $\begin{array}{l}\text { Demirkan et al. (2012), } \\
\text { Barinov et al. (2014), } \\
\text { Jennings and Tanlu (2014) }\end{array}$ \\
\hline Number of subsidiaries (SUB) & Number of subsidiaries of the company. & Cetorelli and Goldberg (2014) \\
\hline $\begin{array}{l}\text { Years the company has operated } \\
\text { (YO) }\end{array}$ & Quanity of years the company has operated in the market. & $\begin{array}{l}\text { Doyle et al. (2007), } \\
\text { Boone et al. (2007), } \\
\quad \text { Farias (2012) }\end{array}$ \\
\hline Size of the company (SIZE) & Natural logarithm of the company's total assets. & $\begin{array}{l}\text { Doyle et al. (2007), } \\
\text { Farias (2012) }\end{array}$ \\
\hline Profitability (ROE) & Return on equity. & $\begin{array}{l}\text { Doyle et al. (2007), } \\
\quad \text { Farias (2012) }\end{array}$ \\
\hline Long term debts (LTD) & Natural logarithm of the balance of long term debts. & $\begin{array}{l}\text { Bushman et al. (2004), } \\
\quad \text { Farias (2012) }\end{array}$ \\
\hline Capital structure (CS) & Ratio between total liabilities and net equity at the end of the period. & Farias (2012) \\
\hline Total complexity (TC) & $\begin{array}{l}\text { Total complexity index created based on the information on industrial, } \\
\text { business, and organizational complexity, which varies from } 0 \text { to } 1 \text {, the } \\
\text { closer to } 1 \text { meaning the greater the complexity. }\end{array}$ & Created by the authors \\
\hline
\end{tabular}

Source: Elaborated by the authors.

The total complexity (TC) variable, presented in Table 1, was developed by the authors, who used the weights of the industrial complexity (IC), business complexity (BC), and organizational complexity variables, by applying the entropy of information, to create a single TC index for each company, by applying the Technique for Order of Preference by Similarity to Ideal Solution (Topsis).
Based on the complexity of companies (independent variables) and conditional conservatism variables observed via the coefficient of estimation from the Khan and Watts (2009) and Banker et al. (2016) models adapted to the Khan and Watts (2009) methodology, new equations were formulated, in order to observe the relationship between IC, BC, and organizational complexity and the level of accounting conservatism adopted by the companies.

$$
\begin{gathered}
A C k w_{i t}=\beta_{0}+\beta_{1} I C_{i t}+\beta_{2} B C_{i t}+\beta_{3} S U B_{i t}+\beta_{4} Y O_{i t}+\beta_{5} S I Z E_{i t}+\beta_{6} R O E_{i t}+\beta_{7} L T D_{i t} \\
+\beta_{8} C S_{i t}+\beta_{9} T C_{i t}+\varepsilon_{i t} \\
A C k w b_{i t}=\beta_{0}+\beta_{1} I C_{i t}+\beta_{2} B C_{i t}+\beta_{3} S U B_{i t}+\beta_{4} Y O_{i t}+\beta_{5} S I Z E_{i t}+\beta_{6} R O E_{i t}+\beta_{7} L T D_{i t} \\
+\beta_{8} C S_{i t}+\beta_{9} T C_{i t}+\varepsilon_{i t}
\end{gathered}
$$

For the data analysis, descriptive statistics, multiple linear regression, and quantile regression were used, calculated by the STATA software. 


\section{DESCRIPTION AND ANALYSIS OF THE RESULTS}

This section presents the description and analysis of the data. Table 2 shows the summary of models 1,2, and 3 , which aim to demonstrate the practice of accounting conservatism adopted by the Brazilian companies analyzed, in accordance with the Basu (1997), Khan and Watts (2009), and Banker et al. (2016) models; in these equations all the companies were analyzed together, without annual weighting, with the aim of only analyzing the conservatism coefficient, and not the relationship sought in the study.

Table 2

Summary of equations 1 (Basu, 1997), 2 (Banker et al., 2016), and 3 (Khan and Watts, 2009)

\begin{tabular}{|c|c|c|c|c|c|c|c|}
\hline \multirow{2}{*}{ Variables } & \multirow{2}{*}{ Coeff. } & Coeff. & Sig. & Coeff. & Sig. & Coeff. & Sig. \\
\hline & & \multicolumn{2}{|c|}{ Basu (1997) } & \multicolumn{2}{|c|}{ Banker et al. (2016) } & \multicolumn{2}{|c|}{ Khan and Watts (2009) } \\
\hline$R_{i t}$ & $\beta_{1}$ & 0.00477 & $0.000 *$ & 0.00446 & $0.000^{*}$ & 0.84471 & 0.455 \\
\hline$D_{i t}$ & $\beta_{2}$ & -0.09429 & $0.013^{*}$ & -0.08430 & $0.035^{*}$ & -0.20330 & 0.536 \\
\hline$D_{i t} \times R_{i t}$ & $\beta_{3}$ & 0.38557 & 0.110 & 0.35379 & 0.140 & -0.95065 & 0.405 \\
\hline$D S_{i t}$ & $\beta_{4}$ & - & - & -0.09749 & $0.011^{*}$ & - & - \\
\hline$\Delta S_{i t} / P_{i t-1}$ & $\beta_{5}$ & - & - & $-5.89 \mathrm{e}-1$ & 0.685 & - & - \\
\hline$D S_{i t} \times \Delta S_{i t} / P_{i t-1}$ & $\beta_{6}$ & - & - & $2.41 \mathrm{e}-10$ & $0.001^{*}$ & - & - \\
\hline$R_{i t} \times$ Size $_{i}$ & $\mu 2$ & - & - & - & - & -0.05014 & 0.534 \\
\hline$R_{i t} \times M / B_{i}$ & 43 & - & - & - & - & 0.00015 & 0.974 \\
\hline$R_{i t} \times \operatorname{Lev}_{i}$ & 44 & - & - & - & - & 0.02012 & 0.744 \\
\hline$D_{i t} \times R_{i t} \times$ Size $_{i}$ & $\lambda_{2}$ & - & - & - & - & 0.03425 & 0.678 \\
\hline$D_{i t} \times R_{i t} \times M / B_{i}$ & $\lambda_{3}$ & - & - & - & - & 0.00142 & 0.795 \\
\hline$D_{i t} \times R_{i t} \times \operatorname{Lev}_{i}$ & $\lambda_{4}$ & - & - & - & - & 0.12333 & 0.169 \\
\hline Size $_{i}$ & $\delta_{1}$ & - & - & - & - & -0.00108 & 0.962 \\
\hline$M / B_{i}$ & $\delta_{2}$ & - & - & - & - & -0.00121 & 0.497 \\
\hline $\operatorname{Lev}_{i}$ & $\delta_{3}$ & - & - & - & - & -0.04617 & $0.028^{*}$ \\
\hline$D_{i t} \times$ Size $_{i}$ & $\delta_{4}$ & - & - & - & - & -0.00057 & 0.980 \\
\hline$D_{i t} \times M / B_{i}$ & $\delta_{5}$ & - & - & - & - & 0.00108 & 0.603 \\
\hline$D_{i t} \times \operatorname{Lev}_{i}$ & $\delta_{6}$ & - & - & - & - & 0.06897 & $0.050^{*}$ \\
\hline \multicolumn{2}{|c|}{$\mathrm{R}^{2}$} & \multicolumn{2}{|c|}{0.1114} & \multicolumn{2}{|c|}{0.1164} & \multicolumn{2}{|c|}{0.4219} \\
\hline \multicolumn{2}{|c|}{ Prob $>\mathrm{F}$} & \multicolumn{2}{|c|}{$0.0000^{*}$} & \multicolumn{2}{|c|}{$0.0000^{*}$} & \multicolumn{2}{|c|}{$0.0000^{*}$} \\
\hline \multicolumn{2}{|c|}{ Fixed effect year } & \multicolumn{2}{|c|}{ Yes } & \multicolumn{2}{|c|}{ Yes } & \multicolumn{2}{|c|}{ Yes } \\
\hline \multicolumn{2}{|c|}{ Fixed effect sector } & \multicolumn{2}{|c|}{ Yes } & \multicolumn{2}{|c|}{ Yes } & \multicolumn{2}{|c|}{ Yes } \\
\hline \multicolumn{2}{|c|}{$\mathrm{n}$} & \multicolumn{2}{|c|}{770} & \multicolumn{2}{|c|}{770} & \multicolumn{2}{|c|}{770} \\
\hline
\end{tabular}

$\Delta S_{i t} / P_{i t-1}=$ change in sales in relation to year $t-1$ and to year $t$ divided by the price of the shares; $D S_{i t} \times \Delta S_{i t} / P_{i t-1}=m u l t i p l i c a t i o n$ of the variables $D S_{i t}$ and $\Delta S_{i t} / P_{t-1} ; D S_{i t}=$ dummy equal to 1 is there is a fall in sales from year $t-1$ to year $t$, and 0 otherwise; $D_{i t}=$ dummy that takes the value of 1 when the return on the share is negative and 0 when it is positive; $D_{i t} \times R_{i t}=$ difference between the impact of the positive and negative returns, with conservatism implying that this coefficient is positive; Lev $v_{i}=$ leverage measured by the long and short term debt deflated by the market value; $M$ / $B_{i}=$ market-to-book; $R_{i t}=$ return on the share; Size ${ }_{i}$ = company size according to the natural logarithm of the market value.

* = significant at $10 \%$.

Source: Elaborated by the authors.

In Table 2, it is observed that the independent variables significantly explain the dependent variable. The explanatory power of the Basu (1997) and Banker et al. (2016) models can be considered low, which may be explained by the difficulty in estimating an accounting phenomenon, conservatism, using an econometric model.

The Khan and Watts (2009) model presents greater explanatory power, which may be due to the addition of the size, market-to-book, and Lev variables, which have a proven relationship, according to this study, with the dependent variable. The relevance of the Khan and Watts (2009) model warrants mentioning, since this presented a $30.55 \%$ improvement in explanatory power in relation to the greater $\mathrm{R}^{2}$ of the other two models.

Regarding the significant independent variables of the Basu (1997) and Banker et al. (2016) models, it is 
perceived that both the $D_{i}$ (dummy for return on the share) and $R_{i}$ (negative returns) variables were shown to be related to the earnings for the period (dependent variable), with the same not occurring with the Khan and Watts (2009) model. In addition, the coefficient of estimation of the variable $(D \times R)$ presented a positive sign in models 1 and 2, although not significant, which does not enable the timely recognition of bad news by the companies analyzed to be confirmed.

Regarding the estimation of conservatism by model 3 , the relationship found is negative, indicating a change in this coefficient with the inclusion of the size, $M / B$, and Lev variables, although not significant. Model 3 highlights debt $(L e v)$ as the determinant variable in explaining the accounting result for the period per company share (PLS).

It was also observed that the cost asymmetry variables from the Banker et al. (2016) model, such as $D S_{i t}$ (dummy for fall in sales) and $D S_{i t} X \Delta S_{i t} / P_{i t-1}$ (change in sales when these are falling), presented a significant influence on the dependent variable earnings, which indicates that earnings were also altered as a result of cost asymmetry, and not only due to accounting conservatism.

Having observed the estimations of conservatism by the models, Table 3 presents the descriptive statistics of the variables used in the main analysis of the relationship between the complexity and accounting conservatism of each company.

Table 3

Descriptive analysis of the variables of equations 7 and 8 - Accounting conservatism scores and complexity variables

\begin{tabular}{|c|c|c|c|c|}
\hline Variables & Minimum & Maximum & Mean & Standard deviation \\
\hline $\begin{array}{c}A C k w_{i t}-\text { Conservatism score according to the Khan } \\
\text { and Watts (2009) model }\end{array}$ & -6.0537 & 3.3554 & -0.2652 & 1.0554 \\
\hline $\begin{array}{c}A C k w b_{i t}-\text { Conservatism score according to the } \\
\text { Banker et al. (2016) model adapted to the Khan and } \\
\text { Watts (2009) methodology }\end{array}$ & -6.4078 & 4.2766 & -0.3136 & 1.2125 \\
\hline$\beta_{i} I C_{i t}-$ Industrial complexity & -0.0480 & 0.7472 & 0.2844 & 0.2429 \\
\hline$\beta_{2} B C_{i t}-$ Business complexity & 1.0000 & 7.0000 & 2.7279 & 1.4902 \\
\hline$\beta_{3} S \cup B_{i t}-$ Subsidiaries & 0.0000 & 109.0000 & 10.2290 & 12.8736 \\
\hline$\beta_{4} Y O_{i t}-$ Years in operation & 0.0000 & 122.0000 & 39.9130 & 27.2302 \\
\hline$\beta_{5} S I Z E_{i t}-$ Company size & 3.1714 & 11.1466 & 7.6585 & 1.4040 \\
\hline$\beta_{6} R O E_{i t}-$ Return on equity & -132.86 & 145.1100 & 9.8764 & 18.6733 \\
\hline$\beta_{7} L T D_{i t}-$ Long term debt & 1.4725 & 10.2348 & 6.6935 & 1.4333 \\
\hline$\beta_{8} C S_{i t}-$ Capital structure & -619.52 & 1616.0916 & 24.4050 & 109.0634 \\
\hline$\beta_{9} T C_{i t}-$ Total complexity & 0.0091 & 0.7915 & 0.2201 & 0.2380 \\
\hline
\end{tabular}

Source: Elaborated by the authors.

Based on Table 3, it is perceived that the proxy for accounting conservatism $\left(A C k w_{i t}\right)$ from the Khan and Watts (2009) model has a minimum with negative values and a maximum with positive values, with it being understood that the company adopts conservative practices when this coefficient presents positive values. It is observed that the mean for the companies (-0.2652) corresponds to the non-adoption of conservative practices. However, as the standard deviation (SD) has a considerable value, with a range of companies with distant values in relation to the mean, a certain disparity is denoted in the sample regarding the adoption of conservative practices. The conservatism proxy estimated by the Banker et al. (2016) model adapted to the Khan and Watts (2009) methodology has similar values to that of the original model, with small variations.

Thus, there is an indication of low recognition of information in a conservative way by the companies analyzed in the period covering 2010 to 2016, which coincides with the obligatory period for CPC 00 (CPC, 2011), which foresees the recognition of information in a neutral way. There is the perception of a possible adherence of the companies listed on the stock exchange to this regulation for neutral recording and a reduction in the use of conservative accounting practices. 
Regarding the IC variables, as these involve a Herfindahl entropy index, there is variation between 0 and 1 , with the mean (0.2844) being closer to 0 , which corresponds to the low IC among the companies analyzed; that is, there are a small number of companies with revenue concentrated in few segments.

The $\mathrm{BC}$ variable shows the quantity of segments in which the companies act, with it being found according to the mean that most operate in fewer than three segments, with a minimum value of one and a maximum of seven operating segments.

The quantity of SUB, considering only the controlled ones, presented a mean of 10 , but with a higher SD than the mean, indicating high dispersion in the data. In addition, there are companies that do not have any control in another company, as well as some companies that control a maximum of 109 . The quantity of YO for the companies varied from zero to 122 , with some operating in their first year. The mean for the companies was almost 40 years.

ROE presented, on average, a positive return on net equity (NE). Both the LTD and the SIZE variables have normalized values, with both having values close to 6 and 7, with low SDs. As for CS, this presented a mean of 24.40 with a high SD.

Finally, TC presented a mean closer to $0(0.2201)$, which indicates that most of the companies presented little complexity in various areas at the same time, with the maximum complexity being 0.7915 .

Having carried out the descriptive statistics for the variables, Table 4 presents the summary of equations 7 and 8 , which measure the influence of the complexity of the companies on the level of accounting conservatism.

Table 4

Summary of equations 7 and 8 - Influence of the complexity variables on levels of conservatism

\begin{tabular}{|c|c|c|c|c|}
\hline \multirow[t]{2}{*}{ Variables } & \multicolumn{2}{|c|}{$\begin{array}{c}\mathbf{A C k w}_{i t} \\
(7)\end{array}$} & \multicolumn{2}{|c|}{$\begin{array}{c}\text { CCkwb }_{i t} \\
(8)\end{array}$} \\
\hline & Coeff. & Sig. & Coeff. & Sig. \\
\hline$\beta_{l} I C_{i t}$ & -0.1147411 & 0.634 & 0.2374754 & 0.385 \\
\hline$\beta_{2} B C_{i t}$ & 0.0320191 & 0.402 & 0.0240654 & 0.585 \\
\hline$\beta_{3} S \cup B_{i t}$ & 0.0206519 & $0.001^{*}$ & 0.0203797 & $0.003^{*}$ \\
\hline$\beta_{4} Y O_{i t}$ & 0.0032236 & 0.214 & 0.0046291 & $0.094^{*}$ \\
\hline$\beta_{5} S I Z E_{i t}$ & -0.0061671 & 0.888 & 0.0291108 & 0.572 \\
\hline$\beta_{6} R O E_{i t}$ & 0.0056206 & $0.009^{*}$ & 0.0042664 & $0.093^{*}$ \\
\hline$\beta_{7} L T D_{i t}$ & -0.0654348 & $0.058^{*}$ & -0.0383648 & 0.258 \\
\hline$\beta_{8} C S_{i t}$ & 0.0000143 & 0.979 & 0.0015696 & 0.337 \\
\hline$\beta_{9} T C_{i t}$ & -5.803408 & $0.008^{*}$ & -5.274703 & $0.035^{*}$ \\
\hline $\mathrm{R}^{2}$ & \multicolumn{2}{|c|}{0.0679} & \multicolumn{2}{|c|}{0.1101} \\
\hline Prob $>F$ & \multicolumn{2}{|c|}{$0.0000^{*}$} & \multicolumn{2}{|c|}{$0.0000^{*}$} \\
\hline Year effect & \multicolumn{2}{|c|}{ Yes } & \multicolumn{2}{|c|}{ Yes } \\
\hline Sector effect & \multicolumn{2}{|c|}{ Yes } & \multicolumn{2}{|c|}{ Yes } \\
\hline $\mathrm{n}$ & \multicolumn{2}{|c|}{713} & \multicolumn{2}{|c|}{721} \\
\hline
\end{tabular}

$\beta_{1} I C_{i t}=$ industrial complexity; $\beta_{2} B C_{i t}=$ business complexity; $\beta_{3} S U B_{i t}=$ subsidiaries; $\beta_{4} Y O_{i t}=$ years in operation; $\beta_{5}$ SIZE $E_{i t}=$ company size; $\beta_{6} R O E_{i t}=$ return on equity; $\beta_{7} L T D_{i t}=$ long term debt; $\beta_{8} C S_{i t}=$ capital structure; $\beta_{9} T C_{i t}=$ total complexity; $A C k w b_{i t}=$ Banker et al. (2016) conservatism score adapted to the Khan and Watts (2009) methodology; $A C \mathrm{kw}_{i t}=K$ Khan and Watts (2009) conservatism score.

* = significant at $10 \%$.

Source: Elaborated by the authors.

Based on Table 4, it is observed that the explanatory power $\left(\mathrm{R}^{2}\right)$ of the equations was low, which has also been observed in international studies (Banker et al., 2016; Khan \& Watts, 2009; LaFond \& Watts, 2008) on this subject. Regarding the significance of the models, these were shown to be significant, demonstrating that the independent variables of complexity significantly explained part of the accounting conservatism adopted by the Brazilian companies. In this stage of the research, outlier information of 3 SDs in relation to the mean was excluded. 
Regarding the independent variables of complexity, it was observed that the ROE, the number of SUB, the TC (equations 7 and 8), the quantity of YO (equation 8), and the LTD (equation 7) were shown to be significantly related to the practicing of conservative results. It can be observed that the higher the return on NE, the number of SUB, and YO, the greater the practicing of accounting conservatism tends to be. In contrast, the higher the LTD and the TC, the lower the level of conservatism tends to be.

With the aim of further explaining the relationships presented by Table 4, Table 5 shows the influence of the complexity variables in different quantiles of accounting conservatism $(10,50,90)$.

\section{Table 5}

Summary of equations 7 and 8 - Influence of the complexity variables on levels of conservatism with 10, 50, and 90 quantile regression for the dependent variable

\begin{tabular}{|c|c|c|c|c|c|c|}
\hline \multirow{4}{*}{ Variables } & \multicolumn{6}{|c|}{ Quantiles } \\
\hline & \multicolumn{2}{|c|}{10} & \multicolumn{2}{|c|}{50} & \multicolumn{2}{|c|}{90} \\
\hline & $\begin{array}{c}A C k w_{i t} \\
(7)\end{array}$ & $\underset{(8)}{C C k w b_{i t}}$ & $\begin{array}{c}C C k w_{i t} \\
(7)\end{array}$ & $\begin{array}{c}C C k w b_{i t} \\
(8)\end{array}$ & $\begin{array}{c}C C k w_{i t} \\
(7)\end{array}$ & $\underset{(8)}{C C k w b_{i t}}$ \\
\hline & Coeff. & Coeff. & Coeff. & Coeff. & Coeff. & Coeff. \\
\hline$\beta_{1} / C_{i t}$ & $-0.56610^{*}$ & -0.01528 & 0.11467 & $0.20546^{*}$ & -0.03746 & 0.19530 \\
\hline$\beta_{2} B C_{i t}$ & $0.11425^{*}$ & $0.13679^{*}$ & 0.00897 & -0.00662 & -0.00595 & -0.01758 \\
\hline$\beta_{3} S \cup B_{i t}$ & $0.03153^{*}$ & $0.02814^{*}$ & $0.00641^{*}$ & $0.01061 *$ & 0.00480 & 0.00910 \\
\hline$\beta_{4} Y O_{i t}$ & $0.00652 *$ & $0.00609 *$ & 0.00071 & $0.00284^{*}$ & 0.00044 & 0.00206 \\
\hline$\beta_{5} S I Z E_{i t}$ & 0.0159 & -0.02203 & 0.02360 & $0.05989 *$ & 0.03507 & 0.04809 \\
\hline$\beta_{6} R O E_{i t}$ & $0.00739 *$ & 0.00595 & 0.00116 & 0.00120 & -0.00012 & -0.00165 \\
\hline$\beta_{7} L T D_{i t}$ & -0.09608 & $-0.13748^{*}$ & -0.02719 & -0.0075 & -0.00698 & -0.01218 \\
\hline$\beta_{8} C S_{i t}$ & -0.00053 & 0.002507 & 0.00060 & $0.00231 *$ & -0.00108 & 0.00117 \\
\hline$\beta_{9} T C_{i t}$ & $-8.8738^{*}$ & $-6.7017^{*}$ & -1.5860 & $-3.892^{*}$ & -2.1772 & -3.3787 \\
\hline $\mathrm{R}^{2}$ & 0.1905 & 0.2079 & 0.0773 & 0.0942 & 0.1249 & 0.1566 \\
\hline Year effect & Yes & Yes & Yes & Yes & Yes & Yes \\
\hline Sector effect & Yes & Yes & Yes & Yes & Yes & Yes \\
\hline
\end{tabular}

$\beta_{1} I C_{i t}=$ industrial complexity; $\beta_{2} B C_{i t}=$ business complexity; $\beta_{3} S U B_{i t}=$ subsidiaries; $\beta_{4} Y O_{i t}=$ years in operation; $\beta_{5}$ SIZE $E_{i t}=$ company size; $\beta_{6} R O E_{i t}=$ return on equity; $\beta_{7} L T D_{i t}=$ long term debt; $\beta_{8} C S_{i t}=$ capital structure; $\beta_{9} T C_{i t}=$ total complexity; $A C k w b_{i t}=B a n k e r$ et al. (2016) conservatism score adapted to the methodology of Khan and Watts (2009); $A C k w_{i t}=K h a n$ and Watts (2009) conservatism score.

* = significant at $10 \%$.

Source: Elaborated by the authors.

According to Table 5, the relationship between conservative practices and company complexity occurs when the levels of conservatism are low and medium, which is not perceived when conservatism is high.

Regarding the significant independent variables, it is shown that ROE (quantile 10), the number of SUB (quantile 10 and 50), the quantity of YO (quantile 10 and 50), BC (quantile 10), SIZE (quantile 50), and CS (quantile 50) showed an influence in terms of increasing the level of accounting conservatism. As for LTD (quantile 10) and TC (quantile 10 and 50), these showed a relationship with a decrease in the practicing of conservative results.
In relation to the IC variable, as this presents a significant influence in terms of decreasing the conservatism in quantile 10 and increasing the conservatism in quantile 50 , it was considered a non-conclusive result when the accounting conservatism quantiles were evaluated, which could be better explored in future studies.

In Table 6, also with the aim of better explaining the relationships of equations 7 and 8 , the same relationship between conservatism and complexity is presented, however with the separation of company samples that presented low, medium, and high TC. 
Table 6

Summary of equations 7 and 8 - Influence of the complexity variables on levels of conservatism for samples with low, medium, and high levels of total complexity

\begin{tabular}{|c|c|c|c|c|c|c|}
\hline \multirow{4}{*}{ Variables } & \multicolumn{6}{|c|}{ Level of complexity } \\
\hline & \multicolumn{2}{|c|}{ Low } & \multicolumn{2}{|c|}{ Medium } & \multicolumn{2}{|c|}{ High } \\
\hline & $\begin{array}{c}A C k w_{i t} \\
(7)\end{array}$ & $\underset{(8)}{C C k w b_{i t}}$ & $\begin{array}{c}C C k w_{i t} \\
(7)\end{array}$ & $\begin{array}{c}C C k w b_{i t} \\
(8)\end{array}$ & $\begin{array}{c}C C k w_{i t} \\
(7)\end{array}$ & $\underset{(8)}{C C k w b_{i t}}$ \\
\hline & Coeff. & Coeff. & Coeff. & Coeff. & Coeff. & Coeff. \\
\hline$\beta_{1} I C_{i t}$ & $-0.5153^{*}$ & 0.12996 & 0.78937 & 0.37012 & 0.14623 & -0.03642 \\
\hline$\beta_{2} B C_{i t}$ & 0.0386 & 0.02550 & 0.08232 & 0.07948 & 0.00220 & 0.03002 \\
\hline$\beta_{3} S \cup B_{i t}$ & $0.01882^{*}$ & 0.00974 & 0.04415 & 0.04094 & 0.04379 & $0.14235^{*}$ \\
\hline$\beta_{4} O Y_{i t}$ & $0.00529 *$ & 0.00309 & 0.00152 & 0.00321 & -0.00140 & 0.00890 \\
\hline$\beta_{5} S I Z E_{i t}$ & 0.00630 & 0.04039 & $1.49864 *$ & $1.15277^{*}$ & $3.21836^{*}$ & $2.91934^{*}$ \\
\hline$\beta_{6} R O E_{i t}$ & 0.00209 & -0.00317 & $0.01092 *$ & $0.00820^{*}$ & 0.01644 & $0.05278^{*}$ \\
\hline$\beta_{7} L T D_{i t}$ & -0.05813 & -0.01374 & $-1.3387^{*}$ & $-0.99530^{*}$ & $-2.45653^{*}$ & $-2.23520^{*}$ \\
\hline$\beta_{8} C S_{i t}$ & 0.00010 & 0.00164 & 0.01091 & 0.00263 & -0.03599 & 0.00169 \\
\hline$\beta_{9} T C_{i t}$ & $-5.6555^{*}$ & -1.322953 & -15.025 & -12.3107 & -52.8146 & -221.183 \\
\hline $\mathrm{R}^{2}$ & 0.1015 & 0.1230 & 0.2281 & 0.2405 & 0.2553 & 0.2153 \\
\hline Prob $>F$ & $0.0000^{*}$ & $0.0000^{*}$ & $0.0000^{*}$ & $0.0000^{*}$ & $0.0000^{*}$ & $0.0000^{*}$ \\
\hline Year effect & Yes & Yes & Yes & Yes & Yes & Yes \\
\hline Sector effect & Yes & Yes & Yes & Yes & Yes & Yes \\
\hline $\mathrm{n}$ & 500 & 503 & 114 & 112 & 99 & 106 \\
\hline
\end{tabular}

$\beta_{1} I C_{i t}=$ industrial complexity; $\beta_{2} B C_{i t}=$ business complexity; $\beta_{3} S U B_{i t}=$ subsidiaries; $\beta_{4} Y O_{i t}=$ years in operation; $\beta_{5} S I Z E_{i t}=$ company size; $\beta_{6} R O E_{i t}=$ return on equity; $\beta_{7} L T D_{i t}=$ long term debt; $\beta_{8} C S_{i t}=$ capital structure; $\beta_{9} T C_{i t}=$ total complexity; $A C k w b_{i t}=B a n k e r$ et al. (2016) conservatism score adapted to the Khan and Watts (2009) methodology; $A C k w_{i t}=K h a n$ and Watts (2009) conservatism score.

* = significant at $10 \%$.

Source: Elaborated by the authors.

The significance of the models is observed, with there being an improvement in the explanatory power of equations 7 and 8 separated by samples of companies with low, medium, and high levels of TC, in relation to the previous analyses.

It was observed that ROE (medium and high levels), the number of SUB (low and high levels), the quantity of YO (low level), and SIZE (medium and high levels) presented an influence in terms of increasing the level of accounting conservatism. However, LTD (medium and high levels) and TC (low level) showed a relationship with reduced conservatism.

IC (low level) showed a relationship with a reduced level of conservatism; however, due to the analysis of Table 5, this variable is also considered to have a nonconclusive explanation in relation to conservatism, as its coefficient presents a positive and negative sign. In relation to the other significant variables, there is an observed tendency for a relationship between these and accounting conservatism, even with the alteration of quantiles and samples.
Based on the above, it was observed that IC did not show a conclusive relationship with the level of accounting conservatism, thus rejecting $\mathrm{H}_{1}$.

This result is consistent with the one obtained by Almeida (2010), which observed that companies adopt a greater degree of accounting conservatism when there is an increase in information asymmetry resulting from competitive environments, which reveals the representativeness of this in relation to the other companies from their operating segment. However, there is a difference between that study and the result of this research, since this research considers IC due to the diversification of revenue from a particular segment compared to other segments of the same company, while Almeida (2010) considered SIZE in relation to the other companies from the segment.

BC presented a significant influence on the adoption of conservatism, especially when this has a low level in the organization, which leads to evidence for the nonrejection of $\mathrm{H}_{2}$. 
In relation to the organizational complexity variables, it was found that return on NE, the number of SUB, the quantity of the company's YO, SIZE, and CS had a significant influence in terms of increasing conservative accounting practices; on the other hand, LTD presented a relationship with decreased conservatism.

As some organizational complexity variables presented a positive relationship with conservatism, $\mathrm{H}_{3}$ is not rejected, although this is not confirmed for all the variables that sought to capture organizational complexity.

These results are consistent with those observed by Farooqi et al. (2014) and Silva (2015), which indicate that companies that have some measures of complexity can adapt practices to improve the quality of information and reduce the information asymmetry caused by complex environments.

According to Farooqi et al. (2014) and Silva (2015), the complexity of companies can be conceived under various measures and thus impact information asymmetry differently, as well as the quality of accounting information. Thus, this result was confirmed by the current study, with the complexity measures BC, ROE, SUB, YO, SIZE, and CS demonstrating a significant influence in terms of increasing the use of conservative practices.
On the other hand, it was found that the TC variable, which shows companies with various complex characteristics at the same time (ID, BC, and organizational), presented a significant relationship with reduced accounting conservatism, thus rejecting $\mathrm{H}_{4}$.

This result for TC may be due to the fact that a company cannot control all its operations when it is complex in various characteristics, which can compromise adoption. Or also, as a possible explanation, companies with various complex characteristics prefer not to adopt a greater degree of accounting conservatism, however much it is convention, due to the bias that it can create in the result, which could possibly increase the perception of information asymmetry between investors even more, as well as its own complexity, as highlighted by LaFond and Watts (2008). According to these authors, accounting conservatism is indicated to reduce information asymmetry; on the other hand, when losses are brought forward and earnings delayed, this can increase the level of asymmetry perceived among investors even more, since it creates bias in the result, which may explain this negative relationship between TC and conservatism.

Based on the results, Table 7 presents the expected sign for the hypotheses, as well as the acceptance or rejection of these.

Table 7

Sign observed for the hypotheses

\begin{tabular}{|c|c|c|}
\hline Hypothesis & Expected sign & Observed sign \\
\hline $\begin{array}{c}\mathrm{H}_{1}: \text { the greater the industrial complexity, the greater the degree } \\
\text { of accounting conservatism }\end{array}$ & Positive & Non-conclusive (positive and negative) \\
\hline $\begin{array}{l}\mathrm{H}_{2} \text { : the greater the business complexity, the greater the degree of } \\
\text { accounting conservatism }\end{array}$ & Positive & Positive \\
\hline $\begin{array}{c}\mathrm{H}_{3}: \text { the greater the organizational complexity, the greater the } \\
\text { degree of accounting conservatism }\end{array}$ & Positive & $\begin{array}{l}\text { Positive, except for the long term debt variable, } \\
\text { which presented a negative sign }\end{array}$ \\
\hline $\begin{array}{c}\mathrm{H}_{4}: \text { the greater the total complexity of companies, the greater } \\
\text { the degree of accounting conservatism }\end{array}$ & Positive & Negative \\
\hline
\end{tabular}

Source: Elaborated by the authors.

Based on Table 7, the observance of a positive sign for $\mathrm{BC}$ and the organizational complexity variables is observed, without considering LTD, as stipulated by the hypotheses. As for the TC variable, this presented an opposite sign to expected, and IC presented a positive sign in some models and a negative one in others, making its result inconclusive, which could be better investigated in future studies.

\section{FINAL REMARKS}

The results showed the estimation of the accounting conservatism adopted by Brazilian companies in the period from 2010 to 2016, according to the Basu (1997), Khan and Watts (2009), and Banker et al. (2016) models. In this study, and in accordance with what was reported by Banker et al. (2016), errors of estimation of conservatism in the original Basu (1997) model were observed in the sample of Brazilian companies, caused by cost asymmetries. 
In the analysis of the relationship between the complexity measures and the conservative accounting practices, the results showed that $\mathrm{BC}$ and organizational complexity, from the perspective of return on $\mathrm{NE}$, quantity of SUB, YO, SIZE, and CS, had an influence in terms of increasing the level of accounting conservatism adopted by the companies.

Considering that the literature foresees that the complexity of companies can limit the transparency of information and lead to a substantial increase in information asymmetry, it is inferred that the companies that presented $\mathrm{BC}$ and organizational complexity (ROE, SUB, YO, SIZE, and CS) may have adopted more conservative accounting practices with the aim of mitigating this asymmetry. This inference is warranted because, in an environment with greater uncertainty, as the environment of complex companies can be characterized, the manager or preparer of accounting statements may opt for more conservative accounting choices, which ultimately generates asymmetric recognition of losses in relation to gains (timely recognition of losses).

It is thus concluded that certain complex firm environments (BC, ROE, SUB, YO, SIZE, and CS) were shown to be related to conservative accounting practices, which may be indicative of a reduction in information asymmetry in such environments. These measures of complexity were associated with an increase in the level of conservatism when analyzed separately, that is, when a company only has $\mathrm{BC}$, for example, and perhaps not the others. On the other hand, the companies that at the same time presented various measures of complexity, to which TC refers, showed a relationship with a reduction in conservative practices.

This result for TC may be connected to the fact that highly complex environments, such as when a company presents the three types of complexity, are more common in large corporations, which have more mechanisms for mitigating informational asymmetry, and where accounting conservatism is not necessary or used less intensely for this. Or, also, according to LaFond and Watts (2008), highly complex companies may be adopting conservatism to a lesser degree with the aim of reducing the external market's perception of asymmetry, seeking to reduce possible political costs resulting from the perception of this practice. However, these aspects were not the object of investigation in this study and could constitute a gap in the research to be explored by future studies.

In addition, as accounting conservatism may be due to numerous other factors, such as accounting standards, the company's organizational culture, manager remuneration, contractual covenants, and taxation factors, among others, the results found in this study need to be viewed with caution, and new studies should be conducted to analyze these aspects. This study did not aim to exhaust the discussion on the topic, which is complex and warrants new analyses.

As a contribution from the study, it was found that accounting conservatism varies depending on the information asymmetry caused by complex environments, in which the relationship depends on whether the company presents complexity in few characteristics (positive relationship) or whether it has complexity in various characteristics at the same time (negative relationship). Therefore, this study sheds light on a new factor or variable that may influence the relationships already studied in the literature between conservatism and its determinants or incentives.

The main implication of this study consists of it suggesting that a more (less) complex organizational environment for companies can influence less (more) conservative accounting practices. This aspect can help explain contradictory results from previous studies on the determinants or incentives of accounting conservatism, as well as helping academics and accounting information users to better understand the more (less) conservative behavior of some companies, which can influence the quality of their reports.

Also, as suggestions for future studies, we recommend an analysis of the complexity of companies in relation to other measures of quality of accounting information, thus contributing to the current study, as well as an analysis of the accounting conservatism in other company environments with a higher or lower level of information asymmetry. We also encourage an analysis of not only accounting and economic but also social information, given that information asymmetry is not restricted to economic and accounting information alone.

\section{REFERENCES}

Almeida, J. E. F. (2010). Qualidade da informação contábil em ambientes competitivos (Doctoral Thesis). Ciências Contábeis, Universidade de São Paulo, São Paulo.
Ball, R., \& Shivakumar, L. (2005). Earnings quality in UK private firms: comparative loss recognition timeliness. Journal of Accounting and Economics, 39(1), 83-128. 
Ball, R., Kothari, S. P., \& Robin, A. (2000). The effect of international institutional factors on properties of accounting earnings. Journal of Accounting and Economics, 29(1), 1-51.

Banker, R. D., Basu, S., Byzalov, D., \& Chen, J. Y. (2016). The confounding effect of cost stickiness on conservatism estimates. Journal of Accounting and Economics, 61(1), 203-220.

Barinov, A., Park, S. S., \& Yildizhan, C. (2014). Firm complexity and post-earnings-announcement drift. Retrieved from https:// ssrn.com/abstract=2360338 or http://dx.doi.org/10.2139/ ssrn. 2360338 .

Basu, S. (1997). The conservatism principle and the asymmetric timeliness of earnings. Journal of Accounting and Economics, 24(1), 3-37.

Baysinger, B., \& Hoskisson, R. E. (1989). Diversification strategy and R\&D intensity in multiproduct firms. Academy of Management Journal, 32(2), 310-332.

Bliss, J. H. (1924). Management through accounts. New York, NY: Ronald Press Company.

Boone, A. L., Field, L. C., Karpoff, J. M., \& Raheja, C. G. (2007). The determinants of corporate board size and composition: an empirical analysis. Journal of Financial Economics, 85(1), 66-101.

Bushman, R., Chen, Q., Engel, E., \& Smith, A. (2004). Financial accounting information, organizational complexity and corporate governance systems. Journal of Accounting and Economics, 37(2), 167-201.

Cardinaels, E., Roodhooft, F., \& Warlop, L. (2004). Customer profitability analysis reports for resource allocation: the role of complex marketing environments. Abacus, 40(2), 238-258.

Cetorelli, N., \& Goldberg, L. S. (2014). Measures of complexity of global banks. Economic Policy Review, 20(2), 1-39.

Chi, W., \& Wang, C. (2010). Accounting conservatism in a setting of Information Asymmetry between majority and minority shareholders. The International Journal of Accounting, 45(4), 465-489.

Comitê de Pronunciamentos Contábeis (Accounting Pronouncements Committee). 2011. CPC 00 (R1) Estrutura conceitual para elaboração e divulgação de relatório contábil-financeiro. Retrieved from http://www. cpc.org.br/CPC/Documentos-Emitidos/Pronunciamentos/ Pronunciamento $? \mathrm{Id}=80$.

Demirkan, S., Radhakrishnan, S., \& Urcan, O. (2012). Discretionary accruals quality, cost of capital, and diversification. Journal of Accounting, Auditing \& Finance, 27(4), 496-526.

Doyle, J. T., Ge, W., \& Mcvay, S. (2007). Accruals quality and internal control over financial reporting. The Accounting Review, 82(5), 1141-1170.

Faria, J. A., Gomes, S. M. S., Dias, J. M., Filho, \& Albuquerque, V. (2011). A assimetria da informação na elaboração do orçamento: uma análise da produção científica nos periódicos internacionais entre 2005 e 2009. Contabilidade Vista \& Revista, 22(2), 43-65.

Farias, K. T. R. (2012). Mecanismos de controle do reporting financeiro das companhias abertas do Brasil (Doctoral Thesis). Accounting, Universidade de São Paulo, São Paulo.
Farooqi, J., Harris, O., \& Ngo, T. (2014). Corporate diversification, real activities manipulation, and firm value. Journal of Multinational Financial Management, 27(C), 130-151.

Hou, K., \& Robinson, D. T. (2006). Industry concentration and average stock returns. The Journal of Finance, 61(4), 19271956.

Jennings, J., \& Tanlu, L. (2014). The effect of organizational complexity on earnings forecasting behavior. Retrieved from https://papers.ssrn.com/sol3/papers.cfm?abstract_ id $=2130119$

Khan, M., \& Watts, R. L. (2009). Estimation and empirical properties of a firm-year measure of accounting conservatism. Journal of Accounting and Economics, 48(2-3), 132-150.

LaFond, R., \& Watts, R. L. (2008). The information role of conservatism. The Accounting Review, 83(2), 447-478.

Linck, J. S., Netter, J. M., \& Yang, T. (2008). The determinants of board structure. Journal of Financial Economics, 87(2), 308328.

Liu, C.-L., \& Lai, S.-M. (2012). Organizational complexity and auditor quality. Corporate Governance: An International Review, 20(4), 352-368.

Ndofor, H. A., Wesley, C., \& Priem, R. L. (2015). Providing CEOs with opportunities to cheat the effects of complexity-based information asymmetries on financial reporting fraud. Journal of Management, 41(6), 1774-1797.

Paulo, E., Antunes, M. T. P., \& Formigoni, H. (2008). Conservadorismo contábil nas companhias abertas e fechadas brasileiras. RAE-Revista de Administração de Empresas, 48(3), 46-60.

Ross, S. A. (1973). The economic theory of agency: the principal's problem. The American Economic Review, 63(2), 134-139.

Roth, K., \& O’Donnell, S. (1996). Foreign subsidiary compensation strategy: an agency theory perspective. Academy of Management Journal, 39(3), 678-703.

Santos, I. C., \& Rodrigues, F. S. S. (2007). Tempo, espaço e as organizações. Revista Brasileira de Gestão e Desenvolvimento Regional, 3(2), 107-123.

Santos, L. S. R., \& Costa, F. M. (2008). Conservadorismo contábil e timeliness: evidências empíricas nas demonstrações contábeis de empresas brasileiras com ADRs negociados na Bolsa de Nova Iorque. Revista Contabilidade \& Finanças, 19(48), 27-36.

Scalzer, R. S., Beiruth, A. X., \& Reina, D. (2017). Empresas estatais e conservadorismo contábil: uma análise das empresas da BM\&FBovespa. REAd. Revista Eletrônica de Administração, 23(2), 333-350.

Silva, A. (2015). Efeito da complexidade empresarial no gerenciamento de resultados de empresas brasileiras (Master's Dissertation). Accounting Sciences, Universidade Regional de Blumenau, Blumenau.

Spence, M., \& Zeckhauser, R. (1971). Insurance, information, and individual action. The American Economic Review, 61(2), 380-387.

Watts, R. L. (2003). Conservatism in accounting part I: explanations and implications. Accounting Horizons, 17(3), 207-221. 